\title{
УДК 622.831:622.274
}

\section{РОЛЬ ГЕОДИНАМИЧЕСКИХ ДВИЖЕНИЙ В ПРОРЫВАХ ВОД В ВЫРАБОТКИ ПРИ РАЗРАБОТКЕ МЕСТОРОЖДЕНИЙ В СЛОЖНЫХ ГИДРОГЕОЛОГИЧЕСКИХ УСЛОВИЯХ}

\author{
Сашурин АнатолийДмитриевич 1 , \\ sashour@igd.uran.ru
}

\author{
Панжин Андрей Алексеевич1, \\ andrey.panzhin@gmail.com
}

\author{
Харисов Тимур Фаритович 1 , \\ timur-ne@mail.ru \\ 1 Институт горного дела УрО РАН, \\ Россия, 620075, г. Екатеринбург, ГСП-219, ул. Мамина-Сибиряка, 58.
}

\begin{abstract}
Актуальность исследования обусловлена широкой распространенностью проблемы предотвращения прорывов водных масс в подземные горные выработки, успешное решение которой во многом определяет эффрективность и безопасность разработки месторождений.
\end{abstract}

Цель: исследование взаимосвязи современных геодинамических движений с опасностью прорыва водных объектов в горные выработки при разработке месторождений в сложных гидрогеологических условиях.

объект: массив месторождений, находящиеся в сложных гидрогеологических условиях, а именно залегающих под мощной осадочной толщей, вмещающей несколько водоносных горизонтов.

Методы: аналитический, спутниковое позиционирование двухчастотными геодезическими GPS приемниками, компьютерное моделирование векторного и тензорного деформационного поля.

Результаты. На основании анализа произошедших аварийных ситуаций, связанных с прорывами вод на рудниках, их причин и способов предупреждения установлено, что одним из важнейших фракторов, вызывающих прорыв водных объектов, являются современные геодинамические движения, формирующие неоднородное мозаичное напряженно-деформированное состояние 8 массиве пород, препятствующее сохранению целостности водозащитных массивов. Известные способы предотвращения опасности прорыва вод в горные выработки путем закладки выработанного пространства и поддержания налегающей толщи целиками при назначении и применении параметров очистных работ без учета фрормирования реального напряженнодеформированного состояния под влиянием геодинамических движений, как правило, сопровождаются авариями. В качестве рекомендаций по предупреждению прорывов вод в горные выработки представлен и апробирован метод изучения геодинамических движений и процессов деформирования, протекающих в массиве, на примере Еланского и Ёлкинского полиметаллических месторождений. Установлены векторы трендовых движения пунктов совместно с тектоническим строением исследуемого региона. Зафиксированы максимальные вертикальные поднятия и максимальные горизонтальные смещения. Результаты измерений обработаны и преобразованы в векторное и тензорное представление деформационного поля, где выделены главные компоненты тензора десормаций.

Выводы. Исследуемый массив находится в умеренной зоне напряженно-деформированного состояния с характерной разнонаправленностью тензора деформаций, что приводит к развитию сдвиговых деформаций в массиве горных пород, отрицательно влияющих на устойчивость горных выработок, а также способствующих раскрытию естественных структурных нарушений массива горных пород и повышению его фильтрационных свойств. Повышение надежности применяемых способов предотвращения опасности прорывов вод в горные выработки требует проведения специальных исследований формирования реального напряженно-деформированного состояния и учета его параметров при проектировании и ведении очистных paбom.

\section{Ключевые слова:}

Прорывы вод, сложные гидрогеологические условия, водные объекты, затопление рудников, геодинамика, тензор деформаций, напряженно-дефоормированное состояние.

\section{Введение}

Критерием сложных гидрогеологических условий подземной разработки месторождений полезных ископаемых принято считать наличие природных или искусственных водных объектов, способных создать аварийные прорывы водных или грязевых масс в горные выработки в процессе их строительства и эксплуатации. К наземным водным объектам относятся искусственные и естественные водоемы. В качестве подземных водных объектов выступают обводненные породы налегающей толщи, именуемые водоносными горизонтами, нередко осложненные карстовыми явлениями.
Относительно небольшое число факторов, создающих неблагоприятные гидрогеологические условия разработки месторождений, при их широкой распространенности выдвигают проблему предотвращения прорывов водных масс в подземные горные выработки в одну из актуальнейших проблем горного дела, успешное решение которой во многом определяет эффективность и безопасность разработки месторождений [1]. В мировой и отечественной горной практике едва ли найдется вид полезного ископаемого, добыча которого не сопровождалась бы аварийными и катастрофическими прорывами вод, в том числе, наряду с экономическим ущербом, и с трагическими последствиями. Особенно чувствительны к прорыву вод в горные выработки соляные шахты, для 
которых они чаще всего завершаются полным затоплением и выводом предприятия из эксплуатации. В зарубежной горной практике насчитывается несколько десятков затопленных соляных шахт. Среди отечественных соляных рудников полностью затоплены СольИлецкая соляная шахта-1 (1979 г.), Березниковский рудник-3 (1986 г.), Березниковский рудник-1 (2006 г.) и в аварийном состоянии пока работает Соликамский рудник-2 [2-5].

В отечественной практике аварийные прорывы подземных вод имели место на десятках угольных шахт Кузбасса [6]. Прорывы вод из подземных и наземных источников происходили в угольные шахты Украины, Казахстана, Киргизии. Затопление шахты «Западная» ООО Компания «Ростовуголь» Новошахтинского угольного бассейна произошло из законсервированной соседней шахты через ее действующий ствол, что воспрепятствовало эвакуации сорока шести шахтеров, которые были спасены через несколько дней после проходки специальной выработки из другой, действующей, соседней шахты [7].

Внезапный прорыв от 150 до 300 тыс. м грязевых масс в 2005 г. на шахте «Соколовская» АО «ССГПО» Казахстана привело к гибели двух человек [8]. Шахта полностью была выведена из строя и приведена в рабочее состояние лишь через 7 месяцев. Катастрофа с затоплением рудника «Мир» компании «Алроса», происшедшая в 2017 г., сопровождалась прорывом около 300 тыс. м воды через предохранительный целик из расположенного выше отработанного карьера. В настоящее время рудник затоплен, из 150 человек, находившихся в момент прорыва под землей, 8 человек не удалось спасти. Экономический ущерб от катастрофы был оценен приблизительно в 7,4 млрд р.

Одним из наиболее трагичных катастроф в международной горной практике является, пожалуй, затопление рудника Замбии «Муфулира», происшедшее в 1970 г. Месторождение, представленное несколькими изолированными участками, залегающими на разных глубинах, было вскрыто до глубины 500 м вертикальными стволами, а нижние горизонты до глубины 1050 м были вскрыты наклонными слепыми стволами. Отработка велась системами с обрушением вмещающих пород. В зону обрушения одного из ранее отработанных локальных участков верхнего этажа на протяжении многих лет складировались флотационные хвосты обогатительной фабрики. В хвостохранилище скопилось около 19,6 млн т отвальной массы, поверхность которой была покрыта водой от стока грунтовых вод, атмосферных осадков и отстоя хвостов.

В сентябре 1970 г. большое количество жидких шламов прорвалось в подземные горные выработки. Эпицентры прорывов располагались в различных местах верхнего этажа разработки. В момент аварии в руднике присутствовало 303 человека, только 214 остались живы. Свидетели этого происшествия утверждают, что шлам прорывался из различных мест и быстро заполнял выработки, уничтожая все на своем пути. Оборудование, буровые станки, погрузочные машины были снесены потоком. Насосные станции были затоплены, и рудник был полностью выведен из строя. Комиссией было установлено, что причиной катастрофы на руднике стала активизация процесса сдвижения горных пород в старой зоне обрушения [9].

Проведенный краткий исторический экскурс по аварийным и катастрофическим случаям прорыва водных объектов в горные выработки подземных горных предприятий, ведущих разработку месторождений в сложных гидрогеологических условиях, позволяет сделать вывод, что решение данной проблемы играет важную роль в обеспечении эффективности и безопасности подземных разработок на протяжении всей истории горного дела и актуальность ее не утрачена на современном этапе его развития.

Техническими расследованиями в рассмотренных выше случаях прорывов вод в горные выработки шахт установлено, что нарушения водозащитных свойств, формирование магистральных водопроводящих трещин и зон в породах водозащитной толщи были вызваны процессом самообрушения горных пород и сдвижением массива над выработанным пространством.

Сохранение целостности водозащитной толщи в сложившейся практике обеспечивается либо применением камерных систем разработки с поддержанием целиками налегающих пород, либо применением систем разработки с закладкой выработанного пространства, в том числе твердеющими смесями. Во многих случаях эти способы обеспечивают успешную разработку месторождений в сложных гидрогеологических условиях. Однако, как следует из приведенных и других многочисленных примеров, при их применении нередко возникают сбои, вызывающие значительные экономические потери и трагические последствия с гибелью людей [10]. Причины сбоев, создающих аварийные и катастрофические ситуации при разработке месторождений под водными объектами, являются предметом исследований, результаты которых приведены в данной работе.

Сбои в предупреждении аварий и катастроф с прорывами вод в горные выработки обусловлены недостаточно точной оценкой устойчивости массива и сохранением водозащитных свойств налегающих пород. В обоих случаях устойчивые безопасные параметры систем разработки и ожидаемые деформации водозащитной толщи определяются исходя из двух факторов - свойств массива горных пород и напряженнодеформированного состояния вмещающего массива. Прогнозные оценки и проектные решения по обеспечению устойчивости горных выработок основываются, как правило, на однородном, стабильном во времени напряженном состоянии со средневзвешенными параметрами напряжений, формируемыми весом налегающих пород. В лучшем случае, при наличии натурных исследований, учитываются дополнительные, чаще всего, горизонтальные тектонические силы. Но принципиально во всех этих случаях напряженнодеформированное состояние принимается относительно однородным и неизменным во времени.

В действительности в массиве формируется неоднородная, мозаичная структура полей напряжений и деформаций и, что очень важно, нестабильная, изме- 
няющаяся во времени [11]. Ее формирование происходит под воздействием двух основополагающих факторов: природной блочной иерархической структуры массива и подвижности блоков под воздействием геодинамики [12-13].

В результате несоответствия параметров очистных камер конкретным геомеханическим условиям возможно самообрушение налегающих пород с нарушением вышележащей водозащитной толщи. Примером подобной ситуации может служить разработка Соколовского железорудного месторождения в Казахстане.

Шахта Соколовская разрабатывает северный фланг Соколовского железорудного месторождения, на южном фланге которого действует одноименный карьер. Месторождение залегает под 120-метровой толщей рыхлых отложений, включающих два мощных водоносных горизонта. Для осушения месторождения в карьерном и шахтном полях были построены подземные кольцевые системы осушения, с помощью которых уровень подземных вод был частично понижен. Шахта проектировалась в 70-е гг. прошлого сто- летия, когда свежа была память трагедии на руднике «Муфулира» Замбии [14]. Под ее влиянием на шахте дополнительно к подземной системе осушения, решившей частично проблему, была запроектирована система разработки с закладкой выработанного пространства твердеющими смесями.

За период с 1975 по 1998 гг. работы шахты системой с закладкой было отработано 432 очистные камеры, из которых в 245 произошли самообрушения пород кровли и висячего бока. Самообрушения 44 камер, пройдя в трубообразной форме через оставленный скальный предохранительный целик и пронизав рыхлые отложения с водоносными горизонтами, вышли на земную поверхность, образовав воронки обрушения, заполненные водой (рис. 1). Происходящий процесс развития сдвижения горных пород, вызвавший прямой доступ грязевых масс из обводненной налегающей рыхлой толщи через образовавшуюся систему воронок обрушения в подземное пространство шахты, сделал бессмысленным дальнейшее применение систем разработки с закладкой.

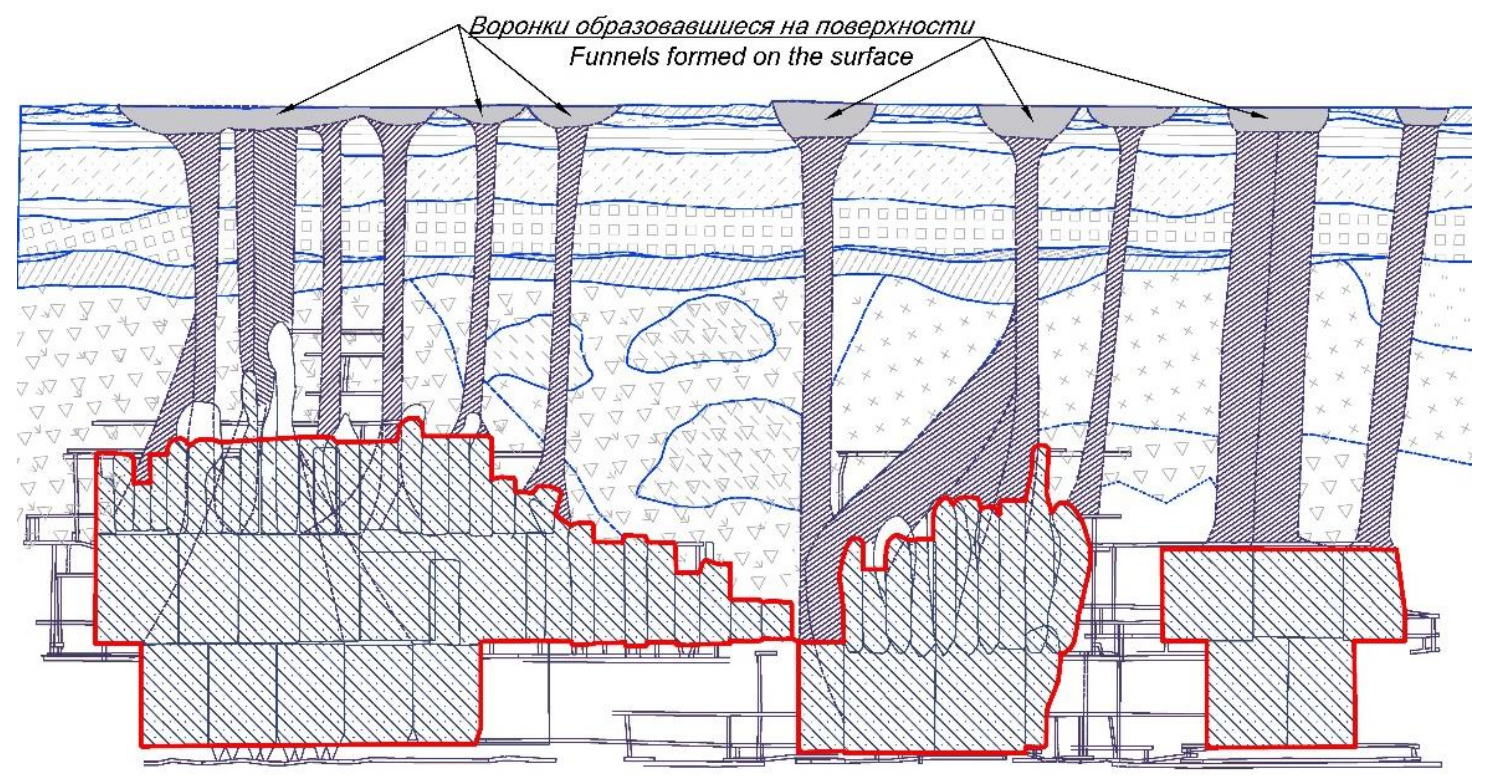

Условные обозначения:

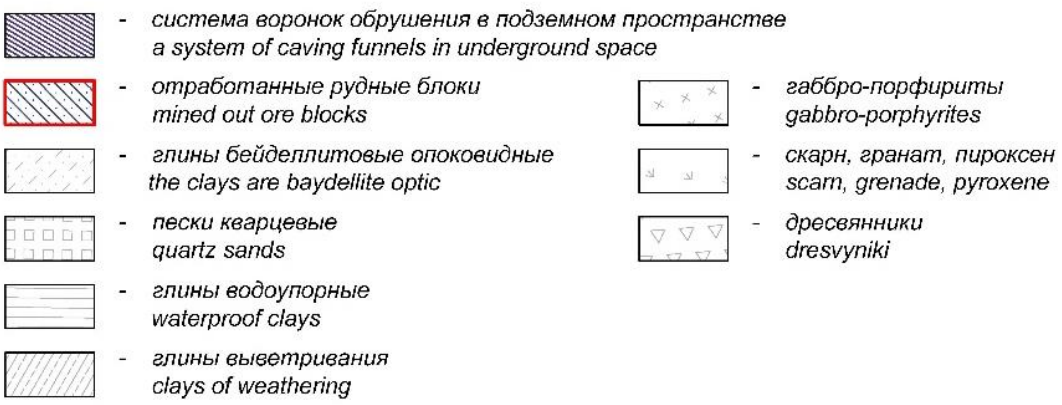

Рис. 1. Развитие воронок обрушения на ш. Соколовская

Fig. 1. Development of caving funnels at Sokolovskaya mine

С 1998 г. шахта Соколовская перешла на системы разработки с обрушением налегающих пород. Начавшийся в период применения систем разработки с закладкой процесс объединения отдельных воронок обрушения в укрупненные зоны обрушения завер- шился в 2005 г. прорывом в подземное пространство шахты грязевых масс. По разным оценкам, как отмечено выше, их объем составил 150-300 тысяч кубических метров, что привело к гибели двух человек. На 7 месяцев все работы на шахте были приостановлены. 
Непосредственная причина, вызвавшая прорыв обводненных рыхлых пород в виде селевой массы в шахту, очевидна - нарушение процессом сдвижения, конкретнее процессом воронкообразования, водозащитной толщи с установлением прямой связи водоносных горизонтов и рыхлых пород покрывающей толщи с подземным пространством шахты. А выяснение причины развития столь многочисленных самообрушений в очистных камерах до их закладки и причины нетипичного развития воронок обрушения в специфичной трубообразной форме с глубин около 300 м потребовало специальных научных исследований [15].
Проведенные ИГД УрО РАН исследования позволили выдвинуть версию, что основу сложившейся катастрофической ситуации создала неоднородная мозаичная структура напряженно-деформированного состояния массива, сформировавшаяся под воздействием геодинамических движений, которая не была известна и не была учтена на стадиях проектирования, строительства и последующей эксплуатации шахты.

На рис. 2 представлено поле деформаций массива горных пород в районе месторождения в виде тензоров главных деформаций, построенное по результатам мониторинга современных геодинамических движений за период с 2012 по 2017 гг.

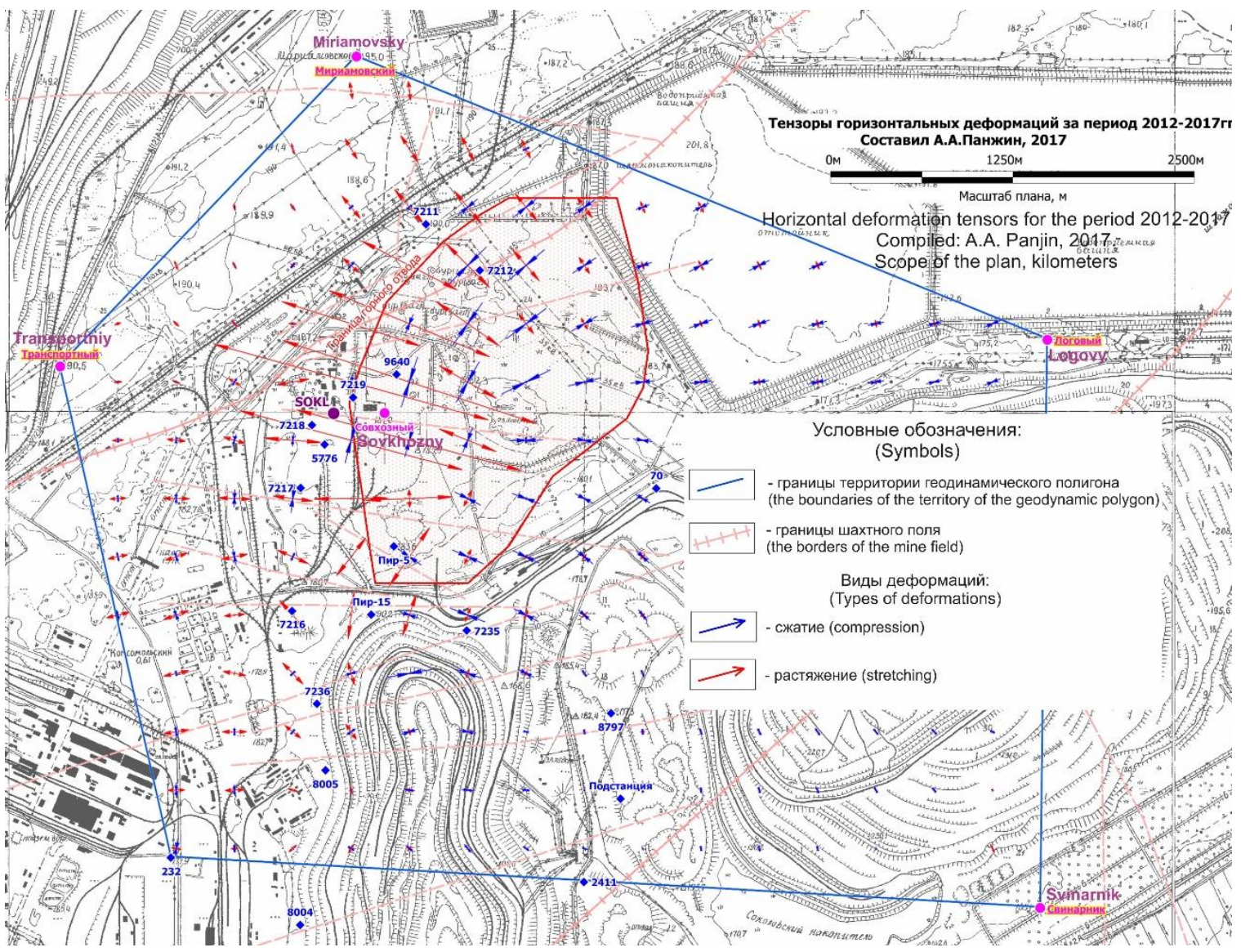

Рис. 2. Тензоры горизонтальных деформаций массива горных пород в районе шахты Соколовская за период с 2012 nо 2017 г2.

Fig. 2. Tensors of horizontal deformation of the massif of rocks near Sokolovskaya mine for 2012-2017

Представленное деформационное поле массива, сформировавшееся под воздействием геодинамических движений, характеризуется тензором разнонаправленных главных деформаций - растяжения и сжатия [16]. Сочетание депрессии, вызванной растягивающими деформациями по одному из главных направлений, со сжимающими деформациями по второму главному направлению ведет к разуплотнению горных пород, раскрытию трещин, образованию сдвиговых деформаций и формированию обрушений. Депрессионное раскрытие трещин от нескольких до десятков сантиметров отмечалось в буровых скважинах эксплуатационной разведки очистных блоков. Повышенный уровень деформаций обоих видов осо- бенно характерен для участка, примыкающего к границе шахтного поля со стороны восстания рудной пачки, в области начала и современного этапа разработки месторождения, чем объясняется повышенная распространенность самообрушений.

Взаимосвязь аномального развития процесса сдвижения с депрессионными зонами, формируемыми современными геодинамическими движениями, установлена при разработке Южной залежи (ш. Северопесчанская), где от разработки очистной камеры размером около $50 \times 50 \times 50$ м на глубине 400 м, вопреки коэффициентам разрыхления, на поверхности образовалась зона обрушения, объем которой превышал объем отработанной камеры. 
Примечательны в этом плане аварии, происшедшие на шахте Магнетитовая Высокогорского ГОКа. 01.10.2009 г. в районе шахтного поля произошло техногенное землетрясение магнитудой 2,3 балла, которое инициировало процесс проседания территории грузовой железнодорожной станции ГОКа, не попадавшей в зону непосредственной подработки. Максимальная величина оседания за счет уплотнения массива в депрессионной зоне, вызвавшая искривление и разрушение всех станционных железнодорожных путей и прилегающих промышленных зданий, составила 1,3 м. Через месяц - 01.11.2009 г. - из соседнего отработанного карьера в шахту прорвались флотационные хвосты обогащения, которые сбрасывались в него в течение нескольких лет. Прорвавшиеся хвосты полностью затопили нижний подготавливаемый этаж, отодвинув срок ввода его в эксплуатацию. Исследования показали, что прорыв хвостов был обусловлен нарушением водозащитных свойств разделительного целика между карьером и шахтой современными геодинамическими движениями, сопровождавшими сейсмическое событие.

Таким образом, приведенные примеры свидетельствуют, что одним из важнейших факторов, вызывающих развитие аварийных ситуаций прорыва водных объектов в шахты, являются современные геодинамические движения, формирующие неоднородное мозаичное поле напряжений в массиве, препятствующее сохранению целостности водозащитных массивов [17].

\section{Методы исследования}

Решение проблемы защиты горных выработок от прорыва водных объектов основывается на сохранении свойств водозащитной толщи, отделяющей горные выработки от водных объектов. Эта задача требует четкого соответствия параметров очистных работ на конкретных участках месторождения реальным геомеханическим условиям, особенно параметрам напряженно-деформированного состояния, формируемого современными геодинамическими движениями [18].

Исследование и мониторинг напряженнодеформированного состояния производится поэтапно. На первом этапе создается геодинамический полигон, геодезические пункты которого охватывают изучаемую территорию залегания месторождения. В состав полигона целесообразно включать, при наличии, постоянно действующие станции GNSS, что позволяет оценить ретроспективно развитие напряженнодеформированного состояния за некоторый предшествующий период [19-22].

На втором этапе на созданном полигоне с заданной периодичностью определяются текущие координаты геодезических пунктов методом спутникового позиционирования двухчастотными приемниками геодезического класса. Приращения координат геодезических пунктов между циклами измерений представляют собой их трендовые движения.

Третий этап посвящается интерпретации инструментальных измерений текущих координат геодези- ческих пунктов. Деформации интервалов между геодезическими пунктами, обусловленные взаимными приращениями координат, с использованием аппарата механики сплошной среды и метода конечных элементов преобразуются и визуализируются в деформационные поля.

\section{Объект исследования}

Предлагаемый подход к предотвращению опасности прорыва подземных вод в шахтные пространства применен к будущим рудникам по разработке Еланского и Ёлкинского полиметаллических месторождений, находящихся в стадии освоения. Еланское и Ёлкинское месторождения представляют собой типичный пример месторождений, залегающих под мощной осадочной толщей, вмещающей несколько водоносных горизонтов.

Объекты находятся на юго-восточном склоне Воронежского кристаллического массива, имеющего ярко выраженное двухъярусное строение. Скальный кристаллический фундамент сложен крепкими (коэффициент крепости по шкале Протодьяконова 15-16) и устойчивыми породами, а осадочный чехол мощностью 200-250 м представлен девонскими, меловыми, палеогеновыми, неогеновыми и четвертичными отложениями [23].

Гидрогеологические условия на участке Еланского и Ёлкинского месторождений схожи и в общем плане определяются их расположением в пределах Приволжско-Хоперского артезианского бассейна. На участке месторождений сформирована единая гидравлическая система, состоящая из водоносных, слабоводоносных, слабоводоупорных и водоупорных горизонтов и комплексов. Еланское месторождение, при мощности осадочной толщи 250 м, вмещает в себе 10 водоносных горизонтов с максимальным дебитом до 3,9 л/с. Ёлкинское месторождение представлено 200 м осадочной толщи, которая вмещает в себе 7 водоносных горизонтов с максимальным дебитом до 3,3 л/с (рис. 3).

Верховодка, донской водно-ледниковый и средневерхнечетвертичный аллювиальные и неогеновый терригенный горизонты (неоген-четвертичный водоносный комплекс) находятся в верхней части общей гидравлической системы. Подземные воды здесь имеют как свободную поверхность, так и, в связи с наличием в кровле глинистых прослоев и линз, местные напоры величиной 2,2-13,4 м; глубина залегания уровня подземных вод изменяется от 10 до $50 \mathrm{M}$.

Водовмещающие породы представлены разнозернистыми песками, иногда глинистыми, суглинками. Мощность всего комплекса на участке работ составляет 120,7 м.

Разгрузка в естественных условиях осуществляется в долину рек Елань.

Питание водоносного комплекса осуществляется за счёт инфильтрации атмосферных осадков и талых вод. Дополнительное питание происходит за счёт подтока из напорных горизонтов верхнего девона.

В основании неогеново-четвертичного комплекса залегают аргиллитоподобные глины верхнего девона. 
Воды неогеново-четвертичного комплекса являются основными для эксплуатации на территории своего распространения. Наиболее водообильным является неогеновый терригенный горизонт. Водопроводимость составляет $326 \mathrm{~m}^{3} /$ сут.

Водовмещающими породами являются песчаники, алевролиты, алевриты.

Гидравлическая связь между горизонтами затруднена из-за наличия в составе водоносных комплексов и между ними водоупорных отложений - аргиллитоподобных глин.

Среди водоупорных пород имеются проницаемые «окна», через которые воды девонской системы имеют гидравлическую связь с подземными водами неогеново-четвертичного комплекса и нижележащей трещиноватой зоной кристаллических пород архей-протерозоя.

Фундамент Воронежского кристаллического массива, вмещающий Еланское и Ёлкинские месторож- дения, нарушен многочисленными тектоническими разломами, которые играют основную роль в формировании структуры осадочного чехла и в особенностях минерагении территории. Их активность влияет на сейсмичность региона, а также на развитие экзогенных геологических процессов [24].

На современном этапе освоения месторождений прогнозная оценка геомеханических условий разработки с позиций влияния современных геодинамических движений на формирование напряженнодеформированного состояние вмещающего массива и опасность прорыва подземных вод в шахтные пространства произведена на региональном уровне, охватывающем территорию с размерами около $200 \times 250$ км, но необходима детализация исследований на уровне района залегания месторождений и шахтных полей.

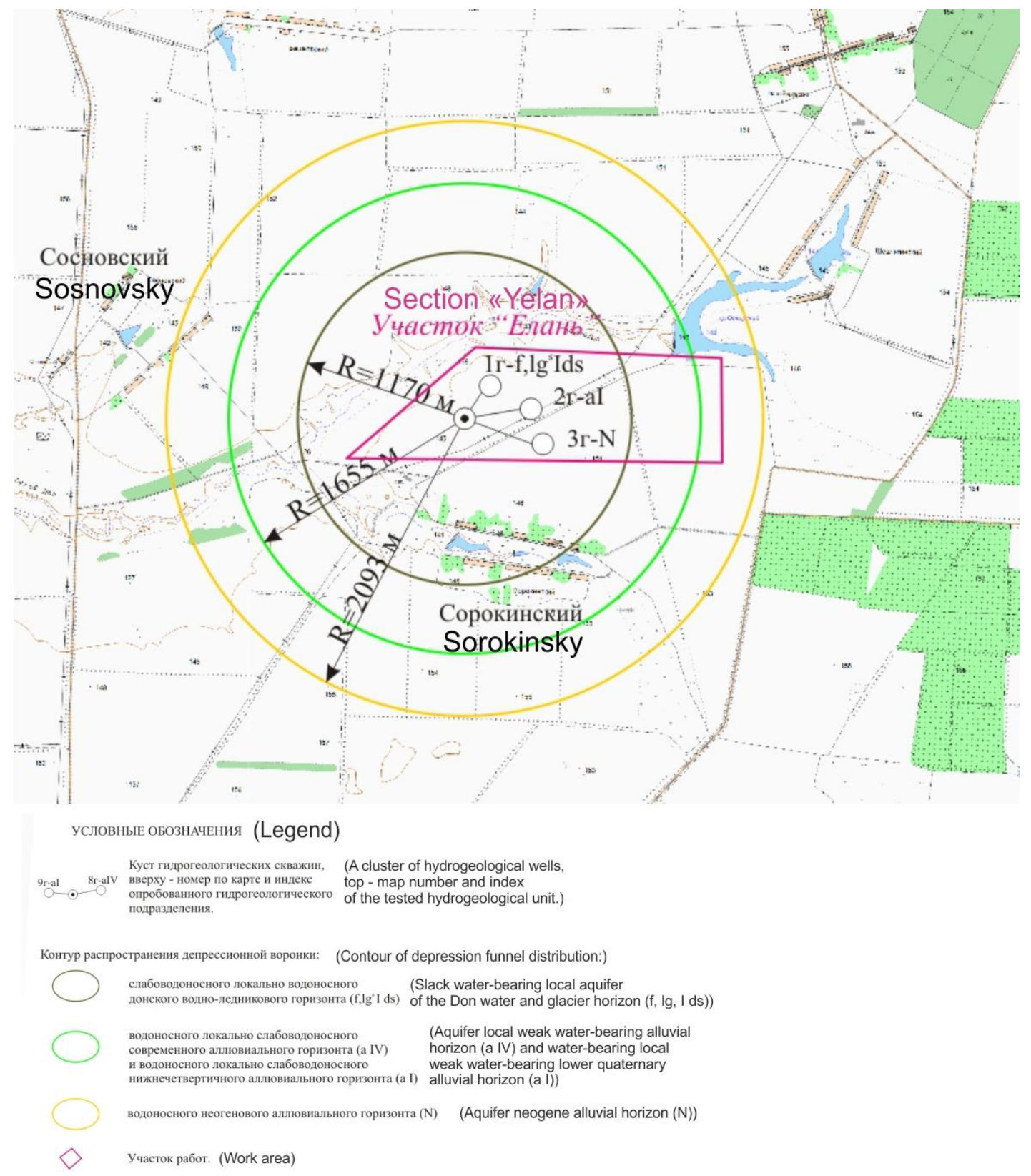

Рис. 3. Карта распространения депрессионной воронки Еланского месторождения

Fig. 3. Map of distribution of depression funnel at Elanskoe deposit 


\section{Результаты исследования}

Исследования осуществлялись с использованием данных мониторинга деформационных процессов, проводимых действующими станциями GNSS на территории исследуемого региона (табл. 1). Для каждого пункта геодинмического полигона определены годовые современные геодинамические движения по трем направлениям - по широте, долготе и высоте. На их основе определялись полные вектора движения в горизонтальной плоскости (2D) и в пространстве (3D).

Векторы трендовых движений пунктов совместно с тектоническим строением региона представлены на рис. 4. Направления и величины векторов характеризуются однородностью и имеют преимущественно восточное направление, что соответствует смещению региона в целом.

Из общей согласованной картины смещений и по величине, и по направленности выделяются вектора смещений пунктов BTRL и KLCH, находящиеся в структурном тектоническом блоке между глубинными разломами Алексеевско-Алексанровским и Шулиминско-Новохоперским. В данном блоке находится эпицентр сейсмического события магнитудой 3,9 баллов, происшедшго в 2000 г., и располагаются Еланское и Ёлкинское месторождения. Также в нем зафиксированы максимальные вертикальные поднятия, составляющие более 30 мм, которые приурочены к району пункта BTRL. Исследуемые месторождения находятся в зоне, где значения вертикальных поднятий близки к максимальным и составляют около 26 мм

Таблица 1. Координаты пунктов GNSS и результаты определения параметров современных геодинамических движений

Table 1. Coordinates of GNSS points and results of modern geodynamic movements parameters determination

\begin{tabular}{|c|c|c|c|c|c|c|c|}
\hline \multirow{2}{*}{ 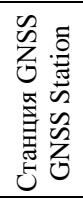 } & \multicolumn{2}{|c|}{$\begin{array}{l}\text { Координаты станции } \\
\text { Station coordinates }\end{array}$} & \multicolumn{5}{|c|}{$\begin{array}{c}\text { Геодинамические } \\
\text { движения, мм/год } \\
\text { Geodynamic movements, } \\
\text { mm/year }\end{array}$} \\
\hline & $\begin{array}{l}\text { В (широта) } \\
\text { B (latitude) }\end{array}$ & $\begin{array}{c}\mathrm{L} \text { (долгота) } \\
\mathrm{L} \text { (longitude) }\end{array}$ & $\Delta \mathrm{B}$ & $\Delta \mathrm{L}$ & $\Delta \mathrm{H}$ & $2 \mathrm{D}$ & $3 \mathrm{D}$ \\
\hline PESK & $51^{\circ} 15^{\prime} 13^{\prime \prime}$ & $42^{\circ} 27^{\prime} 25^{\prime \prime}$ & 41,4 & 8,2 & 29,0 & 42,2 & 51,2 \\
\hline MIHA & $50^{\circ} 04^{\prime} 49^{\prime \prime}$ & $43^{\circ} 13^{\prime} 53^{\prime \prime}$ & 18,8 & 19,6 & 15,2 & 27,2 & 31,1 \\
\hline PAVL & $50^{\circ} 27^{\prime} 39^{\prime \prime}$ & $40^{\circ} 05^{\prime} 55^{\prime \prime}$ & 38,4 & 33,0 & 15,2 & 50,7 & 52,9 \\
\hline VRN3 & $51^{\circ} 55^{\prime} 07^{\prime \prime}$ & $39^{\circ} 17^{\prime} 45^{\prime \prime}$ & 0,0 & 45,3 & 16,6 & 45,3 & 48,3 \\
\hline ALKS & $50^{\circ} 17^{\prime} 06^{\prime \prime}$ & $42^{\circ} 11^{\prime} 21^{\prime \prime}$ & $-6,0$ & 31,4 & 13,8 & 31,9 & 34,8 \\
\hline ANNA & $51^{\circ} 29^{\prime} 07^{\prime \prime}$ & $40^{\circ} 25^{\prime} 21^{\prime \prime}$ & 5,5 & 16,3 & 80,2 & 17,2 & 82,0 \\
\hline BTRL & $50^{\circ} 50^{\prime} 09^{\prime \prime}$ & $40^{\circ} 34^{\prime} 41^{\prime \prime}$ & 17,1 & 71,1 & 34,6 & 73,1 & 80,9 \\
\hline ERTL & $51^{\circ} 50^{\prime} 24^{\prime \prime}$ & $40^{\circ} 46^{\prime} 53^{\prime \prime}$ & 3,0 & 48,9 & 8,3 & 49,0 & 49,7 \\
\hline $\mathrm{KLCH}$ & $50^{\circ} 25^{\prime} 22^{\prime \prime}$ & $41^{\circ} 01^{\prime} 00^{\prime \prime}$ & 11,5 & 36,8 & 16,6 & 38,5 & 42,0 \\
\hline LISK & $50^{\circ} 58^{\prime} 21^{\prime \prime}$ & $39^{\circ} 30^{\prime} 22^{\prime \prime}$ & $-9,4$ & 32,3 & 22,1 & 33,7 & 40,3 \\
\hline PRBD & $50^{\circ} 44^{\prime} 56^{\prime \prime}$ & $43^{\circ} 03^{\prime} 21^{\prime \prime}$ & 3,0 & 37,5 & 27,7 & 37,6 & 46,7 \\
\hline TRKI & $51^{\circ} 59^{\prime} 33^{\prime \prime}$ & $43^{\circ} 16^{\prime} 19^{\prime \prime}$ & 1,3 & 47,3 & 27,7 & 47,3 & 54,8 \\
\hline URPN & $50^{\circ} 47^{\prime} 42^{\prime \prime}$ & $42^{\circ} 00^{\prime} 22^{\prime \prime}$ & 4,7 & 48,6 & 26,3 & 48,8 & 55,5 \\
\hline USMN & $52^{\circ} 03^{\prime} 29^{\prime \prime}$ & $39^{\circ} 44^{\prime} 43^{\prime \prime}$ & 3,8 & 44,7 & 6,9 & 44,9 & 45,4 \\
\hline UVAR & $51^{\circ} 59^{\prime} 10^{\prime \prime}$ & $42^{\circ} 15^{\prime} 22^{\prime \prime}$ & 5,5 & 42,7 & 23,5 & 43,1 & 49,1 \\
\hline VRN1 & $51^{\circ} 40^{\prime} 36^{\prime \prime}$ & $39^{\circ} 10^{\prime} 13^{\prime \prime}$ & $-3,4$ & 34,5 & 31,8 & 34,6 & 47,0 \\
\hline
\end{tabular}

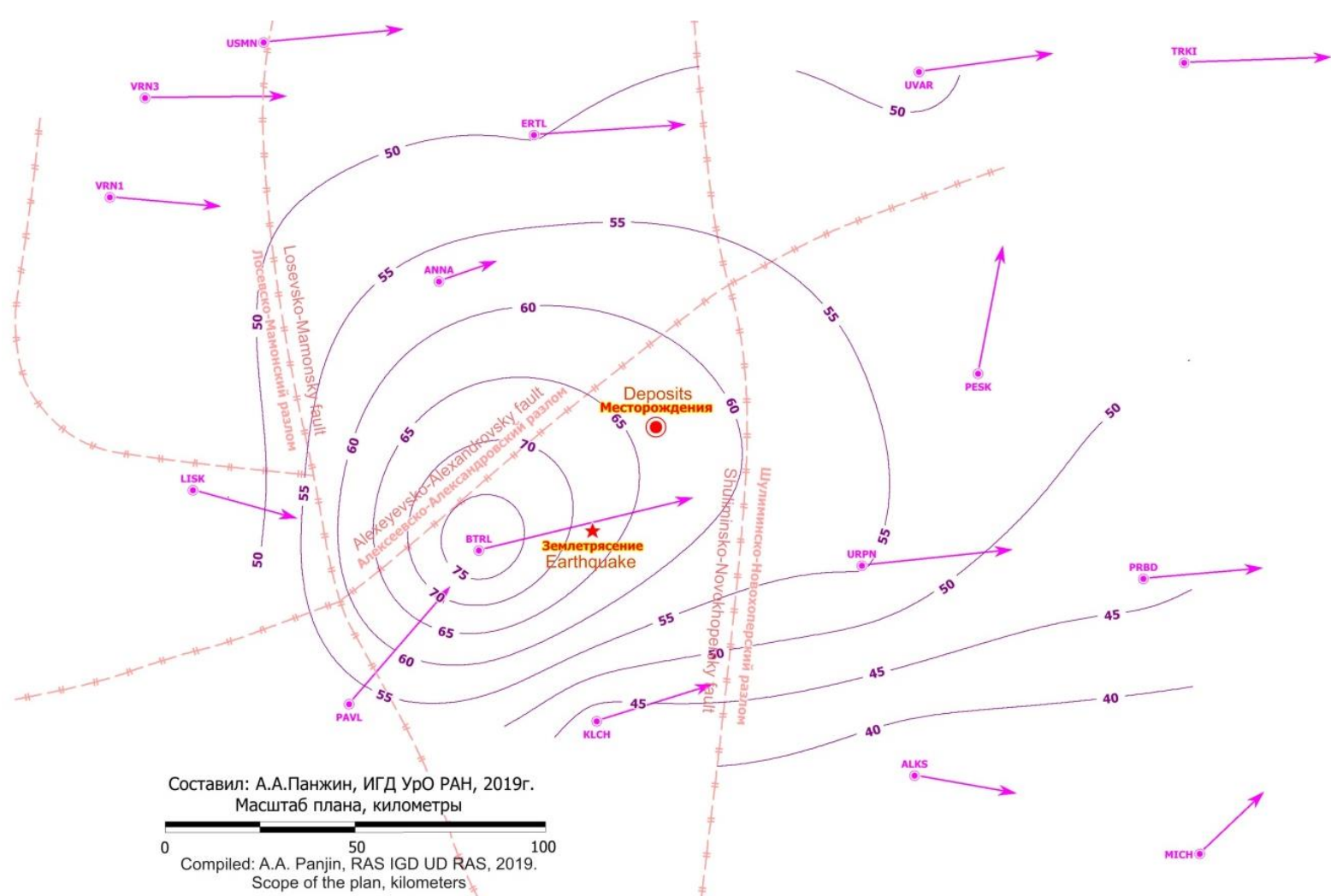

Рис. 4. Распределение векторов и изолиний полных пространственных смещений (3D) на территории исследуемого региона

Fig. 4. Distribution of vectors and isolines of full spatial displacements $(3 D)$ in the territory of the investigated region 
Максимальные горизонтальные смещения в районе пункта BTRL составляют 73,1 мм, минимальные смещения зафиксированы в районе пункта ANNA со значением 17,2 мм. Район Еланского и Ёлкинского месторождений при имеющейся плотности геодезических пунктов находится в умеренной зоне с величинами горизонтальных смещений около 50 мм.

Результаты инструментальных измерений деформаций интервалов между геодезическими пунктами с использованием математического аппарата механики сплошной среды преобразованы в векторное и тензорное деформационное поле с выделением главных компонентов тензора деформаций [25]. На рис. 5 приведена совмещенная схема поля тензоров горизон- тальных главных деформаций, показанная стрелками, а уровень сдвиговых деформаций представлен цветом.

Район размещения Еланского и Ёлкинского месторождений находится в умеренной зоне напряженнодеформированного состояния, но для него характерна разнонаправленность тензора деформаций. То есть в каждой точке действуют одновременно взаимно перпендикулярные сжимающие и растягивающие главные деформации, что приводит к развитию сдвиговых деформаций в массиве горных пород, отрицательно влияющих на устойчивость горных выработок, а также способствующих раскрытию естественных структурных нарушений массива горных пород и повышению его фильтрационных свойств [26].

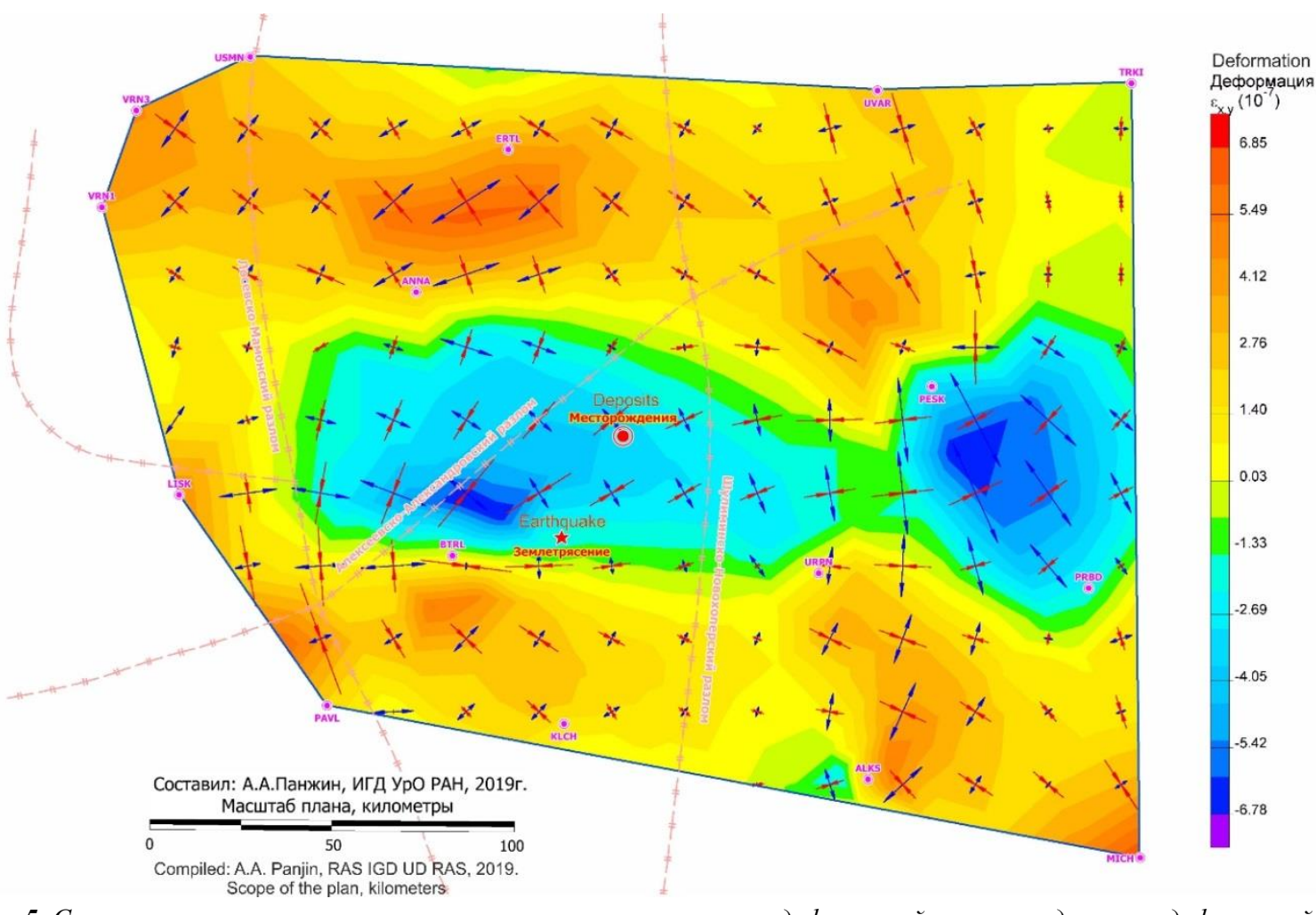

Рис. 5. Совмещенная схема поля тензоров горизонтальных главных деформаций и уровня сдвиговых деформаций

Fig. 5. Combined field diagram of horizontal main strain tensors and shear strain level

\section{Выводы и заключение}

- Результаты исследования взаимосвязи современных геодинамических движений с опасностью прорыва водных объектов в горные выработки при разработке месторождений в сложных гидрогеологических условиях свидетельствуют:

- подземная разработка месторождений в сложных гидрогеологических условиях, создающая опасность аварийных и катастрофических прорывов вод в горные выработки, весьма распространена в горной практике, и проблема их предотвращения сохраняет актуальность на протяжении всей истории горного дела;

- известные способы предотвращения опасности прорыва вод в горные выработки путем закладки выработанного пространства и поддержания налегающей толщи целиками при назначении и при- менении параметров очистных работ без учета формирования фактического поля напряжений образованного в результате воздействия геодинамических движений, как правило, сопровождаются аварийными и, нередко катастрофическими, прорывами вод;

- повышение надежности применяемых способов предотвращения опасности прорывов вод в горные выработки, во многих случаях оправдывающих себя и не имеющих альтернативы, требует проведения специальных исследований формирования реального напряженно-деформированного состояния и учета его параметров при проектировании и ведении очистных работ, что необходимо закрепить в нормативных документах.

Работа выполнена в ходе реализащии государственного задания по теме № 0405-2019-0007. 


\section{СПИСОК ЛИТЕРАТУРЫ}

1. Modeling rock fracture propagation and water inrush mechanisms in underground coal mine / S. Zhang, B. Shen, Y. Li, S. Zhou // Geofluids. - 2019. - V. 1. - P. 1-15.

2. Барях А.А., Красноштейн А.Е., Санфиров И.А. Горнотехнические аварии: затопление первого Березниковского калийного рудника // Вестник Пермского научного центра УрО РАН. 2009. - № 2. - С. 40-49.

3. Батрак Г.И. Закономерности формирования гидродинамического режима затапливаемых шахт // Мониторинг. Наука и технологии. - 2018. - № 4 (37). - C. 41-46.

4. Problems with the application of hydrogeological science to regulation of Australian mining projects: Carmichael Mine and Doongmabulla Springs / M.J. Currell, A.D. Werner, C. McGrath, J.A. Webb, M. Berkman // Journal of Hydrology. - 2017. V. 548. - P. 674-682.

5. Strack O.D.L. Vertically integrated flow in stratified aquifers // Journal of Hydrology. - 2017. - V. 548. - P. 794-800.

6. Костарев А.П., Митишова Н.А. Повышение эффективности мер предупреждения прорывов воды на угольных шахтах // Безопасность труда в промышленности. - 2000. - № 1. C. $35-39$.

7. Мохов А.В., Калинченко В.М., Фролов А.В. Анализ причин и механизма прорыва воды в шахту «Западная» ООО Компания «Ростовуголь» // Безопасность труда в промышленности. - 2005. - № 11. - С. 11-16.

8. Усанов С.В., Крутиков А.В., Мельник Д.Е. Обеспечение промышленной безопасности при разработке Соколовского железорудного месторождения подземным способом в условиях обводненной налегающей толщи // Проблемы недропользования. - 2018. - № 4 (19). - С. 82-89.

9. Головачев Н.К. Катастрофа на руднике «Муфулира» // Горный журнал. - 1971.- № 11. - С. 74-76.

10. Шокин Ю.П. О нарушениях сплошности подработанной водозащитной толщи на калийных рудниках // Горный журнал. 2019. - № 1. - С. 70-75.

11. Сашурин А.Д. Геомеханика в горном деле: фундаментальные и прикладные исследования // Горный журнал. - 2012. № 1. - С. 29-32.

12. Садовский М.А. Иерархия от пылинок до планет // Земля и Вселенная. - 1984. - № 6. -C. 4-9.

13. Innovative approaches to rock mass stability in mining high-grade quartz veins / A.D. Sashurin, A.A. Panzhin, T.F. Kharisov, D.Yu. Knyazev // Eurasian Mining. - 2016. - V. 2. - P. 3-5.

14. Investigation of rockburst in deep underground mines, a case study of Mufulira mine, Copperbelt, Zambia / P. Sinkala, M. Nishihara, Y. Fujii, D. Fukuda, J. Kodama, E. Chanda // 53rd U.S. Rock Mechanics/Geomechanics Symposium. - New York City, USA, 2019. - P. 19-26.
15. Ефремов Е.Ю. Анализ источников водного питания прорывов глинистых отложений в горные выработки Соколовского месторождения // Горный информационно-аналитический бюллетень (научно-технический журнал). - 2020. - № 3-1. - С. 56-67.

16. Балек А.Е. Учет мозаичности напряженно-деформированного состояния массивов скальных горных пород при решении практических задач недропользования // Проблемы недропользования. - 2018. - № 3 (18). - С. 140-150.

17. Сашурин А.Д., Панжин А.А. Современные проблемы и задачи геомеханики // Горный информационно-аналитический бюллетень (научно-технический журнал). - 2020. - № 3-1. C. $188-198$.

18. Risk assessment of floor water inrush in coal mines based on secondary fuzzy comprehensive evaluation / Y. Wang, W. Yang, M. Li, X. Liu // International Journal of Rock Mechanics and Mining Sciences. -2012 . - V. 52. - P. 50-55.

19. Prokos A., Roumpos C. Ground deformation monitoring techniques at continuous surface lignite mines // 4th Joint International Symposium on Deformation Monitoring (JISDM). Athens, Greece, 2019. - P. 98-99.

20. Deformation monitoring and prediction for residential areas in the Panji mining area based on an InSAR time series analysis and the GM-SVR model / Jinchao Li, Fei Gao, Jiaguo Lu, Tingye Tao // Open Geosciences - 2019. - V. 11 (1). - P. 738-749.

21. Huang J., Khan S.D., Ghulam A. Study of subsidence and earthquake swarms in the Western Pakistan // Remote Sensing. 2016.- V. 8 (11). - P. 1-17.

22. Szczerbowski Z. Mining induced seismic events and surface deformations monitored by GPS permanent stations // Acta Geodynamica Et Geomaterialia. - 2015. - V. 12 (3). - P. 237-248.

23. Терентьев Р.А. Никеленосный Еланский комплекс Воронежского кристаллического массива: состав и номенклатура пород // Вестник Воронежского государственного университета. Серия: Геология. - 2020. - № 2. - С. 58-68.

24. Трегуб А.И., Шевцов Д.Е. Разломы в фундаменте восточной части Воронежского кристаллического массива по морфометрическим данным // Вестник Воронежского государственного университета. Серия: Геология. - 2020. - № 1. - С. 30-38.

25. Мазуров Б.Т., Панжин А.А., Силаева А.А. Структурное моделирование полученных по геодезическим данным сдвижений путем визуализации // Геодезия и картография. - 2016. № 3. - C. 35-40.

26. Shen B., Siren T., Rinne M. Modelling fracture propagation in anisotropic rock mass // Rock Mechanics and Rock Engineering. 2015. - V. 48. - № 3. - P. 1067-1081.

Поступила 19.04.2021 2.

\section{Информация об авторах}

Сашурин А.Д., доктор технических наук, ведущий научный сотрудник отдела геомеханики, Институт горного дела УрО РАН.

Панжин А.А., кандидат технических наук, ученый секретарь Института горного дела УрО РАН.

Харисов T.Ф., кандидат технических наук, старший научный сотрудник лаборатории геомеханики подземных сооружений Института горного дела УрО РАН. 
UDC 622.831:622.274

\title{
ROLE OF GEODYNAMIC MOVEMENTS IN WATER BREAKTHROUGHS INTO WORKINGS AT EXPLORATION UNDER DIFFICULT HYDROGEOLOGICAL CONDITIONS
}

\author{
Anatoliy D. Sashurin ${ }^{1}$, \\ sashour@igd.uran.ru
}

\author{
Andrey A. Panzhin 1 , \\ andrey.panzhin@gmail.com \\ Timur F. Kharisov ${ }^{1}$, \\ timur-ne@mail.ru \\ 1 Institute of Mining of Ural Branch of RAS, \\ 58, Mamin-Sibiryak street, Ekaterinburg, 620075, Russia.
}

Relevance of the study is conditioned by wide spread problem of prevention of water mass breakthroughs into underground mine workings, successful solution of which in many respects determines the efficiency and safety of exploration.

The aim of the research is to study the interrelation of modern geodynamic movements with danger of water objects breakthrough into mine workings during development of deposits in difficult hydrogeological conditions.

Object: massif of deposits in difficult hydrogeological conditions, located under a powerful sedimentary stratum containing several aquifers. Methods: analytical, satellite positioning with dual-frequency GPS geodetic receivers, computer simulation of vector and tensor deformation field.

Results. Based on the analysis of occurred emergency situations related to water breakthroughs at the mines, their causes and methods of prevention, it was found that one of the most important factors causing a breakthrough of water bodies are modern geodynamic movements that form a heterogeneous mosaic stress-strain state in the rock mass, which prevents the preservation of the integrity of waterprotective massifs. The known methods to prevent the danger of water breakthrough in the rock by laying the depleted space and maintaining the overlying thickness of the whole, the appointment and application of parameters of treatment works without taking into account the formation of real tensely-deformed state under the influence of modern geodynamic movements are usually accompanied by accidents. As recommendations for prevention of water breakthroughs into the mine workings the method of studying modern geodynamic movements and the stress-strain state formed by them was presented and tested on the example of the massif Elanskoe and Elkinskoe polymetallic deposits. The vectors of trend movements of points together with the tectonic structure of the investigated region are established. Maximum vertical rises and maximum horizontal displacements were fixed. The obtained results of measurements using mathematical apparatus of solid medium mechanics were transformed into vectorial and tensor representation of deformation field with selection of main components of deformation tensor.

Conclusions. The studied array is located in the temperate zone of stress-strain state with a characteristic multi-directionality of the deformation tensor, which leads to the development of shear deformations in an array of rocks, adversely affecting the stability of rock workings, as well as contributing to the disclosure of natural structural disorders of the array of rocks and improvement of its filtration properties. Increase of reliability of applied methods for preventing the danger of water breakthroughs into mine workings demands carrying out of special researches of formation of a real tensely-deformed condition and consideration of its parameters at designing and conducting clearing works.

\section{Key words:}

Water breakthroughs, complex hydrogeological conditions, water bodies, mine flooding, geodynamics, deformation tensor, stress-strain state.

The work was carried out in the course of the state task no. 0405-2019-0007.

\section{REFERENCES}

1. Zhang S., Shen B., Li Y., Zhou S. Modeling rock fracture propagation and water inrush mechanisms in underground coal mine. Geofluids, 2019, vol. 1, pp. 1-15.

2. Baryakh A.A., Krasnoshtein A.E., Sanfirov I.A. Gornotekhnicheskie avarii: zatoplenie pervogo Bereznikovskogo kaliynogo rudnika [Mining accidents: the flooding of the first Bereznikovskiy potash mine]. Vestnik Permskogo nauchnogo centra UrO RAN, 2009, no. 2, pp. 40-49.

3. Batrak G.I. Regularities of formation of the hydrodynamic regime of the flooded mines. Monitoring. Science and technologies, 2018, vol. 4, no. 37, pp. 41-46. In Rus.

4. Currell M.J., Werner A.D., McGrath C., Webb J.A., Berkman M Problems with the application of hydrogeological science to regulation of Australian mining projects: Carmichael Mine and Doongmabulla Springs. Journal of Hydrology, 2017, vol. 548, pp. $674-682$.
5. Strack O.D.L. Vertically integrated flow in stratified aquifers. Journal of Hydrology, 2017, vol. 548, pp. 794-800.

6. Kostarev A.P., Mitishova N.A. Povyshenie effektivnosti mer preduprezhdeniya proryvov vody na ugolnykh shakhtakh [Increase of efficiency of the water breakthrough prevention measures at the coal mines]. Bezopasnost truda v promyshlennosti, 2000, no. 1, pp. 35-39.

7. Mokhov A.V., Kalinchenko V.M., Frolov A.V. Analiz prichin i mekhanizma proryva vody v shahtu «Zapadnaya» OOO Kompaniya «Rostovugol» [The analysis of the reasons and the mechanism of the water breakthrough into the «Zapadnaya» mine, LLC Company «Rostovugol»]. Bezopasnost truda v promyshlennosti, 2005, no. 11, pp. 11-16.

8. Usanov S.V., Krutikov A.V., Mel'nik, D.E. Industrial safety maintenance at development of the Sokolovskiy iron-ore deposit by underground method in the conditions of the waterlogged imposed thickness. Subsurface Exploitation Issues, 2018, vol. 4, no. 19, pp. 82-89. In Rus. 
9. Golovachev N.K. Katastrofa na rudnike «Mufulira» [Disaster at Mufulira mine]. Gorny Zhurnal, 1971, no. 11, pp. 74-76.

10. Shokin Yu.P. About the continuity violations of the processed waterproof thickness at the potash mines. Gornyi Zhurnal, 2019, no. 1, pp. 70-75. In Rus.

11. Sashurin A. D. Geomechanics in mining: fundamental and applied research. Gornyi Zhurnal, 2012, no. 1, pp. 29-32. In Rus.

12. Sadovsky M.A. Ierarkhiya ot pylinok do planet [Hierarchy from dust to planets]. Zemlya $i$ Vselennaya, 1984, no. 6, pp. 4-9.

13. Sashurin A.D., Panzhin A.A., Kharisov T.F., Knyazev D.Yu. Innovative approaches to rock mass stability in mining high-grade quartz veins. Eurasian Mining, 2016, vol. 2, pp. 3-5.

14. Sinkala P., Nishihara M., Fujii Y., Fukuda D., Kodama J., Chanda E. Investigation of rockburst in deep underground mines, a case study of Mufulira mine, Copperbelt, Zambia. 53rd U.S. Rock Mechanics/Geomechanics Symposium. New York City, USA, 2019. pp. 19-26.

15. Efremov E.Yu. Analysis of the water supply sources for the clay deposit breakthroughs in the Sokolovskoye deposit mining.Mining informational and analytical bulletin (scientific and technical journal), 2020, no. 3-1, pp. 56-67. In Rus.

16. Balek A.E. Mosaic of the stress-strain state of the rock masses at solution of the practical problems of the subsoil use. Subsurface Exploitation Issues, 2018, vol. 3, no. 18, pp. 140-150. In Rus.

17. Sashurin A.D., Panzhin A.A. Modern problems and problems of the geomechanics. Mining informational and analytical bulletin (scientific and technical journal), 2020, no. 3-1, pp. 188-198. In Rus.

18. Wang Y., Yang W., Li M., Liu X. Risk assessment of floor water inrush in coal mines based on secondary fuzzy comprehensive evaluation. International Journal of Rock Mechanics and Mining Sciences, 2012, vol. 52, pp. 50-55.
19. Prokos A., Roumpos C. Ground deformation monitoring techniques at continuous surface lignite mines. $4^{\text {th }}$ Joint International Symposium on Deformation Monitoring (JISDM). Athens, Greece, 2019. pp. 98-99.

20. Li J., Gao F., Lu J., Tao T. Deformation monitoring and prediction for residential areas in the Panji mining area based on an InSAR time series analysis and the GM-SVR model. Open Geosciences, 2019, vol. 11, no. 1, pp. 738-749.

21. Huang J., Khan S.D., Ghulam A. Study of subsidence and earthquake swarms in the Western Pakistan. Remote Sensing, 2016, vol. 8, no. 11, pp. 1-17.

22. Szczerbowski Z. Mining induced seismic events and surface deformations monitored by GPS permanent stations. Acta Geodynamica Et Geomaterialia, 2015, vol. 12, no. 3, pp. 237-248.

23. Terentev R.A. The Nickeliferous Elan complex of the Voronezh crystalline massif: composition and nomenclature of the rocks. Proceedings of Voronezh State University. Series: Geology, 2020, no. 2, pp. 58-68. In Rus.

24. Tregub A.I., Shevtsov D.E. Fractures in the foundation of the eastern part of the Voronezh crystalline massif on morphometric data.Proceedings of Voronezh State University. Series: Geology, 2020, no. 1, pp. 30-38. In Rus.

25. Mazurov B.T., Panzhin A.A., Silayeva A.A. Structural modeling obtained by the geodesic given nym displacement by visualizing. Geodesy and Cartography, 2016, no. 3, pp. 35-40. In Rus.

26. Shen B., Siren T., Rinne M. Modelling fracture propagation in anisotropic rock mass. Rock Mechanics and Rock Engineering, 2015, vol. 48, no. 3, pp. 1067-1081.

Received: 19 April 2021.

Information about the authors

Anatoliy D. Sashurin, Dr. Sc., leading researcher, Institute of Mining of Ural Branch of RAS.

Andrey A. Panzhin, Cand. Sc., scientific secretary, Institute of Mining of Ural Branch of RAS.

Timur F. Kharisov, Cand. Sc., senior researcher, Institute of Mining of Ural Branch of RAS. 